\title{
Factors Associated with Depression and Anxiety Severity in Multiple Sclerosis Patients
}

\author{
(1) Meral Seferoglu1*, (1) Nizameddin Koca22, (1) Ali Ozhan Sivaci ${ }^{1}$, (1) Sukran Yurtogullari3 \\ 1 University of Health Sciences Turkey, Bursa Yuksek Ihtisas Training and Research Hospital, Department of Neurology, Bursa, Turkey \\ 2University of Health Sciences Turkey, Bursa Yuksek Ihtisas Training and Research Hospital, Department of Internal Medicine, Bursa, Turkey \\ 3 Private Bursa Hayat Hospital, Bursa, Turkey
}

\section{Abstract}

Objective: The most common psychiatric comorbidities with multiple sclerosis are depression and anxiety. The Beck Depression Inventory (BDI) and Hamilton Anxiety Scale (HAM-A) are validated tests that are easy to administer and interpret, and are widely used to determine depression and anxiety, respectively. The aim of our study is to examine the association of depression and anxiety levels via the BDI and HAM-A with disease duration, disability, and treatments in patients with Multiple sclerosis (MS).

Materials and Methods: One hundred sixty-three MS patients who gave consent were included in the study. The BDI for depression and HAM-A scales for anxiety were applied. MS patients were analyzed in two subgroups: Relapsing-Remitting and progressive groups. Disability was evaluated with the Expanded Disability Status Scale (EDSS).

Results: A total of 163 patients, including 116 women and 47 men, had a mean age of 38.50 9.63 years, and the mean duration of MS diagnosis was $7.49 \pm 6.18$ years. The rate of anxiety was $82.2 \%$ and depression was $33.7 \%$ according to HAM-A and BDI scale, respectively. In subgroup analysis, it was observed that anxiety and depression scores of RRMS patients were significantly lower than progressive subtypes. Anxiety and depression scores of patients with EDSS $\leq 3$ were found to be significantly lower than those with EDSS $>3$. We found that disease modifying treatments did not have a significant effect on anxiety and depression scores.

Conclusion: In our study, it was observed that depression and anxiety were closely related to MS type and disability. The appropriate treatment of accompanying depression and anxiety is crucial for the management of the MS disease process.

Keywords: Multiple sclerosis, depression, anxiety, Beck Depression Inventory, Hamilton Anxiety Scale

\section{Introduction}

Multiple sclerosis (MS) is a neurodegenerative central nervous system (CNS) disease characterized by inflammation, demyelination, and axon damage. The incidence and prevalence of MS is increasing. It is the most common cause of disability in young adults after trauma $(1,2)$. The etiology of MS is multifactorial and progresses with different clinical presentations. MS can progress with attacks and remissions, or with a progressive disease course. Clinical signs and symptoms may show individual differences. Visual, sensory, cerebellar, and psychiatric symptoms can be seen (3).
Psychiatric symptoms such as mania, hallucinations, and depression in MS patients were first described by Charcot et al. (4). Compared to the normal population, depression, anxiety, cognitive dysfunction, bipolar disorder, and psychosis are more common in MS patients (5). Studies have reported that $95 \%$ of the MS population are associated with psychiatric comorbidities throughout life. The most common psychiatric comorbidities are depression and anxiety disorder.

It has been reported that the lifetime prevalence of depression in MS patients varies between $19 \%$ and $54 \%$, and in crosssectional studies, the point prevalence of clinically important

Address for Correspondence: Meral Seferoglu, University of Health Sciences Turkey, Bursa Yuksek Ihtisas Training and Research Hospital, Department of Neurology, Bursa, Turkey E-mail: meralbozseferoglu@gmail.com ORCID-ID: orcid.org/0000-0003-3858-0306

Received: 21.10.2021 Accepted: 28.01.2022

${ }^{\circ}$ Copyright 2021 by the Journal of Multiple Sclerosis Research published by Galenos Publishing House. 
depressive findings is observed to be up to $50 \%(6,7)$. Although the signs and symptoms of depression are common in MS patients, studies have shown that the rate of missed diagnoses is quite high and they are treated inadequately. In the study conducted by Mohr et al. (8), it was determined that $65.6 \%$ of MS patients with depression did not receive treatment, and only $26.6 \%$ were under appropriate treatment. Depression and anxiety disorders are treatable comorbid diseases. If they are treated, the quality of life will increase and the follow-up will be easier in MS treatment compliance and in the followup process. The important thing is to recognize and question the signs of depression and anxiety during the outpatient clinic applications.

In the MS diagnosis process, questioning the psychiatric history and screening are important for the management of immunomodulatory therapies. There are studies showing that interferons, which have been used in the treatment of MS for many years, may cause depression and should not be used in patients with a previous history of depression (9). On the other hand, there are study findings showing that the treatments did not have negative psychiatric effects and that some treatments reduced the incidence of depressive symptoms (10). There is no consensus on the effects of the treatments used in MS on depression and anxiety.

The pathogenesis of MS, localization of lesions, clinical presentation, progressive course, treatments used, and psychosocial factors have been shown as triggering factors for psychiatric disorders. Compared to other chronic diseases, psychiatric disorders accompanying MS were found to be associated with greater fatigue, poor quality of life, and decreased adherence to treatment (11). For these reasons, early diagnosis and treatment of psychiatric disorders that are present at the time of admission or that develop later are very important for the management of the disease course. In the intensive outpatient setting, the focus is on the neurological examination and anamnesis of MS, and psychiatric comorbidities may be overlooked.

The Beck Depression Inventory (BDI) and Hamilton Anxiety Scale (HAM-A) are validated tests that are easy to administer and interpret, and are widely used to determine depression and anxiety. The aim of our study is to investigate the association between depression and anxiety levels via the BDI and HAM-A with disease duration, disability, and disease modifying treatments in patients with MS.

\section{Materials and Methods}

Patients who were followed up in Bursa Yuksek Ihtisas Training and Research Hospital MS outpatient clinic and diagnosed with MS according to the 2010 McDonald diagnostic criteria were evaluated cross-sectionally (12). After the ethics committee approval of the study was obtained from Yuksek Ihtisas Training and Research Hospital Ethics Committee, 163 MS patients who agreed to participate in the study and signed the informed consent form were included in the study. Age, gender, disease duration, EDSS scores, and disease modifying treatments used for MS were recorded at the time of admission. The BDI for depression and HAM-A scales for anxiety were applied.

\section{Inclusion Criteria:}

- Diagnosis with MS according to the 2010 McDonald criteria,

- Being between the ages of 18 and 65 years,

- Having no additional neurological disease,

- Not having a diagnosis of depression and/or anxiety by psychiatry prior to the time of the test,

- Not having received methylprednisolone treatment and/or attack treatment in the last 3 months,

- Being at least a primary school graduate,

- Not having a disease that would affect cognitive performance,

- Agreed to participate in the study.

\section{Exclusion Criteria:}

- Having a serious comorbid systemic disease,

- Stated that they would not be able to comply with the study and did not sign the consent form.

The patients constituted the Relapsing-Remitting (RR) Relapsing-Progressive (RP), and Primary Progressive (PP) groups. Analyses were done by forming two groups, RR and progressive forms (RP + PP). The disability of MS patients was evaluated with the Expanded Disability Status Scale (EDSS). The EDSS is a method of quantifying disability in MS and monitoring changes in the level of disability over time. The scale was developed by the neurologist John Kurtzke in 1983 and is widely used in clinical trials and in the assessment of people with MS (13). The patients were divided into two groups according to their EDSS scores. Those with EDSS $\leq 3$ were grouped to represent patients with no or mild disability, and those with EDSS $>3$ were grouped to represent patients with moderate and severe disability (14).

\section{Scales}

Beck Depression Inventory (BDI): The purpose of this test is to measure the level of depressive symptoms; a high total score indicates the severity of the depression level. It can be self-applied. There are 21 questions, and the maximum possible score is 63 . The cut-off point in this test, for which validity and reliability studies were conducted for the Turkish population, was determined as 17 (15-17)

Hamilton Anxiety Scale (HAM-A): This scale, developed by Hamilton, which questions the physical and mental effects of anxiety, consists of two parts. Yazıcı et al. (18) conducted the validity and reliability of the scale (19). In this test with a 
maximum score of 56, a score between 6 and 14 points was considered as minor and a score of 15 and above was considered as major anxiety. Those who scored 6 or higher on the HAM-A scale were considered to have anxiety.

\section{Statistical Analysis}

All statistical analyses were performed using SPSS (Statistical Package for the Social Sciences) version 26. For each continuous variable, data normality was confirmed using the KolmogorovSmirnov test $(p>0.05)$. Pearson's correlation was used to examine the relationships among the measured variables. For independent groups categorized by the MS subtype and EDSS, an independent sample t-test was performed for the normally distributed data. A Bonferroni correction was used to determine the source of significance. In the comparison of categorical variables, the chi-square test was utilized. P values less than 0.05 were considered significant.

\section{Results}

A total of 163 patients, including 116 women and 47 men, were included in our study. The mean age of the patients was $38.50 \pm 9.63$ years, and the mean duration of MS diagnosis was $7.49 \pm 6.18$ years. The mean value of HAM-A and BDI are given along with sociodemographic characteristics in Table 1. It was determined that $82.2 \%$ of the patients had a score 6 or higher on the HAM-A scale. $33.7 \%$ of the patients had a score 17 , determined as depression.

The relationships between the patients' age, MS duration, and HAM-A and BDI scales were evaluated. A positive correlation was found between the HAM-A and BDI scales. While a significant correlation was observed between the patient's age and MS duration, no correlation was found between these variables and anxiety and depression scales (Table 2).

There was a significant relationship between MS type and depression and anxiety scales. In subgroup analyses, the anxiety and depression scores of RR MS patients were significantly lower than progressive (PP and RP) subtypes (Table 3).

There was a significant relationship between EDSS scores and MS duration, anxiety and depression scores. Anxiety and depression scores of patients with EDSS $\leq 3$ were found to be significantly lower than those of patients with EDSS >3 (Table 4).

\begin{tabular}{|l|l|l|}
\hline \multicolumn{2}{|l|}{ Table 1. Sociodemographic data } \\
\hline & $\begin{array}{l}\text { Mean } \pm \text { SD } \\
(n=163)\end{array}$ & $\begin{array}{l}\text { Median, } \\
\text { min-max }\end{array}$ \\
\hline Age, years & $38.50 \pm 9.63$ & $39,18-64$ \\
\hline MS duration, years & $7.49 \pm 6.18$ & $6,0-28$ \\
\hline HAM-A (0-56) & $25.46 \pm 10.96$ & $13,0-48$ \\
\hline BDI (0-63) & $13.58 \pm 9.28$ & $11,0-42$ \\
\hline
\end{tabular}

MS: Multiple sclerosis, HMA-A: Hamilton Anxiety Rating Scale, BDI: Beck Depression Inventory, SD: Standard deviation
Patients with different disease modifying treatments had similar anxiety and depression scores (Table 5).

\section{Discussion}

Depression and anxiety were found to be related to EDSS scores and clinical subtypes while no correlation was observed with MS duration. BDI and HAM-A scores were found to be significantly higher in RPMS and PPMS patients. No relationships were found with age, gender, and disease duration. According to our study, $\mathrm{BDI}$ and HAM-A scores were associated with disability and the progressive course of the disease. We did not find any correlations between treatments and scores of BDI and HAM-A scales.

The onset and symptoms of MS vary among individuals. The initial symptom may be a visual and sensory attack that can be easily diagnosed, or it may be a psychiatric complaint that can make the path to diagnosis long and difficult. Studies show that the frequency at which MS starts with psychiatric complaints varies from 1 to $2.3 \%$, suggesting that the problem is only the tip of the iceberg $(20,21)$. In another study conducted in psychiatry clinics, it was stated that $0.83 \%$ of the magnetic resonance images performed in patients diagnosed with psychiatry had hyperintense lesions and they met the diagnostic criteria for MS. It has been shown in the literature that the rate of psychiatric diagnosis before MS is diagnosed is 9\%. In another study, the rate of being diagnosed with depression in MS patients was reported as 52\% $(22,23)$. It was reported that the diagnosis time of patients whose first MS attack started with psychiatric complaints was delayed by 7 years (24). This delayed period is a very important and lost time for the early treatment of the disease.

Psychiatric comorbidities with MS have long been recognized. In a comprehensive review of MS and accompanying comorbid diseases, it was shown that depression and anxiety affect more than $20 \%$ of the MS population $(5,25)$. The psychiatric symptoms that appear at the beginning resolve later than the neurological symptoms, and complete well-being does not occur most of the time (21). It is thought that showing the presence of accompanying psychiatric symptoms from the beginning may also be a determinant of psychiatric morbidity that may

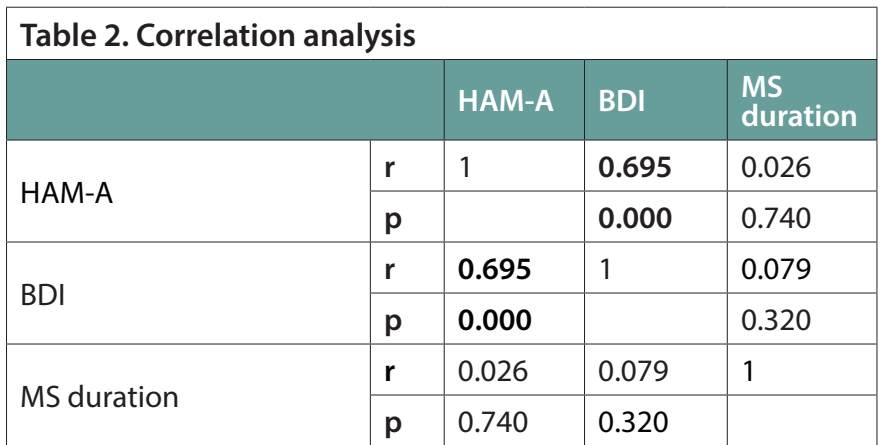

HMA-A: Hamilton Anxiety Rating Scale, BDI: Beck Depression Inventory, MS: Multiple sclerosis, r: Pearson's correlation coefficient, p: Probability 


\begin{tabular}{|c|c|c|c|c|c|}
\hline & & $R R(n=137)$ & $P P+R P(n=26)$ & Total $(n=163)$ & $p$ value \\
\hline \multirow[b]{2}{*}{ MS Duration } & Mean \pm SD & $6.95 \pm 6.10$ & $10.40 \pm 5.89$ & $7.48 \pm 6.18$ & \multirow[b]{2}{*}{0.005} \\
\hline & Median, min-max & $5,0-28$ & $10.5,1-22$ & $6,0-28$ & \\
\hline \multirow[b]{2}{*}{ HAM-A } & Mean \pm SD & $14.17 \pm 10.69$ & $22.23 \pm 10.01$ & $15.46 \pm 10.96$ & \multirow[b]{2}{*}{$<0.001$} \\
\hline & Median, min-max & $12,0-48$ & $23,7-43$ & $13,0-48$ & \\
\hline \multirow[b]{2}{*}{ BDI } & Mean \pm SD & $12.27 \pm 8.76$ & $20.46 \pm 9.06$ & $13.58 \pm 9.28$ & \multirow[b]{2}{*}{$<0.001$} \\
\hline & Median, min-max & $10,0-42$ & $18,7-37$ & $11,0-42$ & \\
\hline
\end{tabular}

HMA-A: Hamilton Anxiety Rating Scale, BDI: Beck Depression Inventory, RR: Relapsing remitting, PP: Primary progressive, RP: Relapsing progressive, MS: Multiple sclerosis

\section{Table 4. Evaluation of the relationship between disability status score and variables}

\begin{tabular}{|l|l|l|l|l|l|}
\hline \multicolumn{2}{|c|}{} & $\begin{array}{l}\text { EDSS } \leq 3 \\
(n=122)\end{array}$ & $\begin{array}{l}\text { EDSS }>3 \\
(n=41)\end{array}$ & $\begin{array}{l}\text { Total } \\
(n=163)\end{array}$ \\
\hline \multirow{3}{*}{ MS duration } & Mean \pm SD & $6.53 \pm 5.78$ & $10.40 \pm 6.51$ & $7.48 \pm 6.18$ \\
\hline \multirow{3}{*}{ HAM-A } & Median, min-max & $5,0-22$ & $11,0-28$ & $6,0-28$ & 0.001 \\
\hline \multirow{3}{*}{ BDI } & Mean \pm SD & $13.97 \pm 10.85$ & $19.88 \pm 10.20$ & $15.46 \pm 10.96$ \\
\cline { 2 - 6 } & Median, min-max & $11,0-48$ & $17,5-44$ & $13,0-48$ & $<0.001$ \\
\hline
\end{tabular}

HMA-A: Hamilton Anxiety Rating Scale, BDI: Beck Depression Inventory, EDSS: Expanded disability status scale, MS: Multiple sclerosis

Table 5. Evaluation of the relationship between MS drugs and variables

\begin{tabular}{|c|c|c|c|c|c|c|c|c|}
\hline & $\begin{array}{l}\text { Interferon } \\
(n=50)\end{array}$ & $\begin{array}{l}\text { Glatiramer } \\
\text { acetate }(n=34)\end{array}$ & $\begin{array}{l}\text { Oral drugs } \\
(n=78)\end{array}$ & $\begin{array}{l}\text { Total } \\
(n=162)\end{array}$ & P value & P1* & P2* & P3* \\
\hline MS duration & $6.27 \pm 4.93$ & $5.56 \pm 5.93$ & $9.18 \pm 6.69$ & $7.49 \pm 6.18$ & 0.006 & $>0.99$ & 0.020 & $>0.99$ \\
\hline BDI & $13.70 \pm 10.73$ & $11.74 \pm 7.46$ & $14.26 \pm 9.05$ & $13.58 \pm 9.28$ & 0.458 & $>0.99$ & $>0.99$ & 0.569 \\
\hline
\end{tabular}

HMA-A: Hamilton Anxiety rating scale, BDI: Beck Depression Inventory, MS: Multiple sclerosis

P1: Interferon vs. Glatiramer acetate, P2: Interferon vs. oral drugs, P3: Glatiramer acetate vs. oral drugs

*: Adjusted p-value with Bonferroni correction

accompany in the later period. Depression accompanying MS has been found to be associated with an increased risk of suicide, in addition to its adverse effects on the course of the disease, cognitive functions, treatment compliance, and quality of life (6). Studies have shown that accompanying depression during diagnosis of MS is overlooked at a rate of $23-30 \%$ and it is not treated at a rate of $20-36 \%(6,26,27)$. Depression and anxiety disorders are treatable illnesses once diagnosed. The combination of some symptoms such as insomnia, loss of appetite, introversion, and distraction may make the physician suspect the diagnosis of depression, but most of the time, the patients have difficulty in expressing themselves. These symptoms should be considered and questioned. There are scales that question these symptoms and offer a more detailed and objective evaluation. BDI, one of the commonly used assessment scales, was used in our study (17).

In our study, BDI and HAM-A scores showed a positive correlation with each other. There are a few studies in the literature examining the effects of anxiety and depression on each other in MS patients. In a study conducted with 189 MS patients in 2017, it was shown that the presence of anxiety was a risk factor for depression, both directly and indirectly (28). Regular screening and treatment of anxiety symptoms may be recommended to reduce the risk of depression.

Many studies have investigated the relationship between the severity of the illness and the symptoms of depression and/ or anxiety. In the literature, it has been shown that there is an increase in the incidence and severity of depression and anxiety symptoms with worsening neurological symptoms and an increase in disability (29). In the same study, mild anxiety rates were found to be $38 \%$ for those with low disability and $66.7 \%$ for those with high disability. The rates of those experiencing mild depression symptoms were found to be $17.1 \%$ for those with low disability and $71.1 \%$ for those with high disability (29). In our study, a significant positive correlation was found between increased disability scores and anxiety and depression, 
which is in line with the literature. BDI and HAM-A scores were found to be significantly higher in RPMS and PPMS patients. Relationships with age, gender, and disease duration have also been shown in the literature. In our study, no relationships were found with age, gender, and disease duration. According to our study, BDI and HAM-A scores were associated with disability and the progressive course of the disease.

Considering the relationship between disease modifying treatments and psychiatric comorbidities in MS, studies on interferon (IFN) therapy, which has been used in MS treatment for a long time, are encountered. In the literature, it has been shown that IFN therapy can cause depression in cancer, hepatitis C, MS, and skin diseases. Although it was reported that depressive symptoms started with IFN treatment and improved after IFN treatment was terminated, this relationship could not be fully demonstrated in subsequent studies $(30,31)$. A systematic literature review study investigating the relationship between depression and IFN treatment, which was published in 2017, shows that the relationship has not been clearly demonstrated, but the presence of a history of depression in the past is a risk factor for developing depression in the first six months of IFN treatment (9). In the MS diagnosis process, questioning the psychiatric history and screening are important for early diagnosis of individuals at risk and for the management of immunomodulatory therapies. In a systematic literature review of psychiatric complaints associated with natalizumab, fingolimod, dimethyl fumarate, teriflunomide, and alemtuzumab in MS, changes in anxiety or depression scores following treatment were also examined as a secondary goal. As a result of the study, findings revealed that the treatments did not have negative psychiatric effects, and that some treatments reduced the incidence of depressive symptoms. It has been argued that this may be related to the direct immunomodulatory effects of treatments and indirectly to their positive effects on disease activity (10). Inflammation, serotonin, norepinephrine, glutamate, brain derived neurotrophic factor and regulatory disorders in the hypothalamic-pituitary axes have been listed as common pathways for depression and MS. The effective treatment of depression and the regulatory effect of the antidepressant treatment on these pathways may provide a secondary benefit such as neuroprotection (32). In our study, we did not find any correlation between treatments and scores of the BDI and HAM-A scales. However, the use of scales in terms of monitoring depression and anxiety symptoms during the treatment process provides convenience for the early diagnosis of psychiatric comorbidities, as suggested in the literature. Treating depression in MS alters the course of the disease positively by affecting treatment compliance, cognitive impairment, pathological fatigue, quality of life, and reducing cytokine production (6).
MS is a lifelong chronic disease that may cause severe disability in young adults. Accompanying psychiatric signs and symptoms, especially depression and anxiety, can cause loss of function, increase in disability, and mislead in the treatment process of MS. It is important to diagnose and treat psychiatric comorbidities early for accurate follow-up of MS.

\section{Study Limitations}

Small sample size and unequal distribution of subgroups can be considered as the limitations of our study.

\section{Conclusion}

Our results show a positive association of BDI and HAM-A scores with disability and progression of MS. The appropriate treatment of accompanying depression and anxiety is crucial for the management of the MS disease process. Screening scales, which can be performed at certain intervals during clinical visits, may be useful for the diagnosis of comorbid psychiatric diseases in patients.

\section{Ethics}

Ethics Committee Approval: This study was approved by the Ethics Committee of Bursa Yuksek Ihtisas Training and Research Hospital (decision no: 2011-KAEK-25 2016/13-21, date: 13.07.2016).

Informed Consent: It was obtained.

Peer-review: Externally and internally peer-reviewed.

\section{Authorship Contributions}

Surgical and Medical Practices: M.S., A.O.S., S.Y., Concept: M.S., A.O.S., S.Y., Design: M.S., A.O.S., Data Collection or Processing: M.S., N.K., S.Y., Analysis or Interpretation: M.S., N.K., Literature Search: M.S., N.K., Writing: M.S.

Conflict of Interest: The Authors declare no conflict of Interest.

Financial Disclosure: The authors declared that this study received no financial support.

\section{References}

1. Pugliatti M, Rosati G, Carton H, Riise T, Drulovic J, Vécsei L, Milanov I. The epidemiology of multiple sclerosis in Europe. Eur J Neurol 2006;13:700-722.

2. Oh J, Vidal-Jordana A, Montalban X. Multiple sclerosis: clinical aspects. Curr Opin Neurol 2018; 31: 752-759

3. Compston A, Coles A. Multiple sclerosis. Lancet 2008;372:1502-1517.

4. Butler MA, Bennett TL. In search of a conceptualization of multiple sclerosis: a historical perspective. Neuropsychol Rev 2003;13:93-112.

5. Marrie RA, Reingold S, Cohen J, Stuve O, Trojano M, Sorensen PS, Cutter G, Reider N. The incidence and prevalence of psychiatric disorders in multiple sclerosis: a systematic review. Mult Scler 2015;21: 305-317.

6. Skokou M, Soubasi E, GourzisP. Depression in multiple sclerosis: a review of assessment and treatment approaches in adult and pediatric populations. ISRN Neurol 2012;2012:427102

7. ChwastiakL, Ehde DM, Gibbons LE, Sullivan M, Bowen JD, Kraft GH. Depressive symptoms and severity of illness in multiple sclerosis: epidemiologic study 
of a large community sample. Am J Psychiatry 2002;159:1862-1868.

8. Mohr DC, Hart SL, Fonareva I, Tasch ES. Treatment of depression for patients with multiple sclerosis in neurology clinics. Mult Scler 2006;12:204-208.

9. Alba Palé L, León Caballero J, Samsó Buxareu B, Salgado Serrano P, Pérez Solà V. Systematic review of depression in patients with multiple sclerosis and its relationship to interferonbeta treatment. Mult Scler Relat Disord 2017;17:138-143

10. Gasim M, Bernstein CN, Graff LA, Patten SB, El-Gabalawy R, Sareen J, Bolton JM, Marriott JJ, Fisk JD, Marrie RA; CIHR team "Defining the burden and managing the effects of psychiatric comorbidity in chronic inflammatory disease. Adverse psychiatric effects of disease-modifying therapies in multiple Sclerosis: A systematic review. Mult Scler Relat Disord 2018;26:124156.

11. Feinstein A, Magalhaes S, Richard JF, Audet B, Moore C. The link between multiple sclerosis and depression. Nat Rev Neurol 2014;10:507-517.

12. Polman CH, Reingold SC, Banwell B, Clanet M, Cohen JA, Filippi M, Fujihara K, Havrdova E, Hutchinson M, Kappos L, Lublin FD, Montalban X, O'Connor P, Sandberg-Wollheim M, Thompson AJ, Waubant E, Weinshenker B, Wolinsky JS. Diagnostic criteria for multiple sclerosis: 2010 revisions to the McDonald criteria. Ann Neurol 2011;69:292-302.

13. Kurtzke JF. Rating neurologic impairment in multiple sclerosis: an expanded disability status scale (EDSS). Neurology 1983;33:1444-1452.

14. Xue $H$, Yang Z, Wang L, Jiang $Y$, Li J, Wu M, Wang G, Zhang Y, Zhang M. Factors Influencing the Degree of Disability in Patients With Multiple Sclerosis. Front Neurol 2021;12:714631.

15. Hisli N. Beck depresyon envanterinin üniversite öğrencileri için geçerliği, güvenirliği. Psikoloji Dergisi 1989;7:8-13.

16. Köroğlu E, Aydemir Ö. Psikiyatride kullanılan klinik ölçekler. Hekimler Yayın Birliği 2009:93-335.

17. Beck AT, Ward CH, Mendelson M, Mock J, Erbaugh J. An inventory for measuring depression. Arch Gen Psychiatry 1961;4:561-571.

18. Yazıcı MK, Tanrıverdi N, Karaağaoğlu E, Yolaç P. Hamilton Anksiyete Değerlendirme Ölçeği, değerlendiriciler arası güvenirlik ve geçerlilik çalışması. Turk Psikiyatri Dergisi 1998;9:114-117.

19. Hamilton M. The assessment of anxiety states by rating. Br J Med Psychol 1959;32: 50-55
20. Jongen PJ. Psychiatric onset of multiple sclerosis. J Neurol Sci 2006:245:5962.

21. Lo Fermo S, Barone R, Patti F, Laisa P, Cavallaro TL, Nicoletti A, Zappia M. Outcome of psychiatric symptoms presenting at onset of multiple sclerosis: a retrospective study. Mult Scler 2010;16:742-748.

22. Skegg K, Corwin PA, Skegg DC. How often is multiple sclerosis mistaken for a psychiatric disorder? Psychol Med 1988;18:733-736.

23. Sullivan MJ, Weinshenker B, Mikail S, Edgley K. Depression before and after diagnosis of multiple sclerosis. Mult Scler 1995;1:104-108.

24. Berna F, Blanc F, Lebrun C, Castelnovo G, Clerc C, Debouverie M, Jouvenoz D, Marcel-Viallet M, Zaenker C, Zephir H, Vidailhet P, De Sèze J. Should a psychotic or manic episode be considered an early manifestation of Multiple Sclerosis? A multiple case study. Mult Scler Relat Disord 2016;6:9396.

25. Chalah MA, Ayache SS. Psychiatric event in multiple sclerosis: could it be the tip of the iceberg? Braz J Psychiatry 2017;39:365-368.

26. McGuigan C, Hutchinson M. Unrecognised symptoms of depression in a community-based population with multiple sclerosis. J Neurol 2006;253:219-223.

27. Cetin K, Johnson KL, Ehde DM, Kuehn CM, Amtmann D, Kraft GH Antidepressant use in multiple sclerosis: epidemiologic study of a large community sample. Mult Scler 2007;13:1046-1053.

28. Gay MC, Bungener C, Thomas S, Vrignaud P, Thomas PW, Baker R, Montel S, Heinzlef O, Papeix C, Assouad R, Montreuil M. Anxiety, emotional processing and depression in people with multiple sclerosis. BMC Neurol 2017;17:43.

29. Jones KH, Jones PA, Middleton RM, Ford DV, Tuite-Dalton K, LockhartJones H, Peng J, Lyons RA, John A, Noble JG. Physical disability, anxiety and depression in people with MS: an internet-based survey via the UK MS Register. PLoS One 2014;9:e104604.

30. Loftis JM, Hauser P. The phenomenology and treatment of interferoninduced depression. J Affect Disord 2004;82:175-190.

31. Feinstein A. Multiple sclerosis, disease modifying treatments and depression: a critical methodological review. Mult Scler 2000;6:343-348.

32. Grech LB, Butler E, Stuckey S, Hester R. Neuroprotective Benefits of Antidepressants in Multiple Sclerosis: Are We Missing the Mark? J Neuropsychiatry Clin Neurosci 2019;31:289-297. 